\title{
THE EFFECT OF MIDAZOLAM AND PROPOFOL FOR CONSCIOUS SEDATION IN THIRD MOLAR SURGERY
}

\author{
Mohammad Ali R. Patel'1, Muhammad Haneef², Irfan Waris ${ }^{3}$, Ankita Hajare 4 \\ ${ }^{1}$ Assistant Professor, Department of Dentistry and Maxillofacial Surgery, KBN Institute of Medical Sciences, Kalaburagi. \\ ${ }^{2}$ Registrar, Department of Maxillofacial Surgery, MOH, Asir Region, KSA. \\ ${ }^{3}$ Assistant Professor, Department of Anaesthesiology, KBN Institute of Medical Sciences, Kalaburagi. \\ 4Junior President, Department of Anaesthesiology, KBN Institute of Medical Sciences, Kalaburagi.
}

\section{ABSTRACT}

\section{BACKGROUND}

Objectives- The present study was conducted to assess the effects of low dose Midazolam and continuous infusion of Propofol along with local anaesthesia in third molar surgeries to evaluate the level of sedation, haemodynamic changes, post-operative amnesia, condition of the patient during surgery, patient satisfaction and opinion.

\section{MATERIALS AND METHODS}

25 ASA Grade I and II patients between the age group of 21 to 45 years, both male and female; who required surgical removal of third molars were selected. Patients received a low dose Midazolam bolus of $0.03 \mathrm{mg} / \mathrm{kg}$ prior to Propofol bolus of $0.7 \mathrm{mg} / \mathrm{kg}$ followed by continuous infusion of Propofol at 50 microgram $/ \mathrm{kg} / \mathrm{min}$. Haemodynamic and respiratory parameters were monitored and recorded pre-operatively, intra-operatively and post-operatively at different time intervals. The level of sedation, amnesia and conditions of each patient were evaluated during the study. Patient's satisfaction was recorded using a modified Visual Analogue Scale (VAS). All results were evaluated statistically.

\section{RESULTS}

Haemodynamic and respiratory parameters remained stable throughout the procedures. The level of sedation for $75 \%$ patients had a sedation score of 3 during the operative procedure. Patient condition was rated excellent during the operative procedure in $72 \%$ patients by the surgeon. The psychomotor functions had improved by 60 th minute postoperatively.

\section{CONCLUSION}

Conscious sedation using a low dose Midazolam with continuous infusion of Propofol along with local anaesthesia is a good and safe option for third molar surgeries as it produces superior quality sedation without serious complications.

\section{KEYWORDS}

Conscious Sedation; Intravenous Sedation; Propofol; Midazolam; Amnesia.

HOW TO CITE THIS ARTICLE: Patel MAR, Haneef M, Waris I, et al. The effect of midazolam and propofol for conscious sedation in third molar surgery. J. Evolution Med. Dent. Sci. 2017;6(35):2879-2884, DOI: 10.14260/Jemds/2017/621

\section{BACKGROUND}

Third molar surgical procedures are performed routinely under local anaesthesia which is a rather unpleasant experience. General anaesthesia on the other hand demands a more specialised operatory setup, accurate monitoring and subsequently increases the treatment cost. The possibility of anaesthetic complications can also be considered as cardinal drawback of general anaesthesia.

Pain associated with these surgical procedures can be managed effectively through the administration of local anaesthetics; however, administration of local anaesthetic is also considered to be a traumatic procedure by most patients, and hence incites a fear of pain amongst them, increasing fear and apprehension. 1,2,3,4,5,6

Financial or Other, Competing Interest: None.

Submission 17-02-2017, Peer Review 30-03-2017,

Acceptance 05-04-2017, Published 01-05-2017.

Corresponding Author:

Dr. Mohammad Ali R Patel

Assistant Professor,

Department of Dentistry and Maxillofacial Surgery,

KBN Institute of Medical Sciences,

Kalaburagi.

E-mail:dr.ali_omfs@yahoo.com

DOI: $10.14260 /$ jemds $/ 2017 / 621$
These apprehensive patients can therefore be managed by inducing an altered state of consciousness in which a person is more relaxed and carefree than previously.

Various intravenous drugs have been used over the past decades for conscious sedation; each one of them having certain advantage and disadvantage upon each other. The various drugs used to produce conscious sedation are; Benzodiazepines (Diazepam, midazolam), Barbiturates (Pentobarbital, Methohexital), Histamine blockers (Promethazine), Opioid agonists (Meperidine, fentanyl) and other drugs like Ketamine and Propofol. The two most popular agents used for conscious sedation are propofol and midazolam as they have many advantages over other agents.

Propofol was introduced in 1985 and has been available for clinical practice since 1989 in the United States. ${ }^{7}$ Since then, its use in outpatient oral and maxillofacial surgery has increased significantly. Propofol has got qualities that make it an effective and excellent agent for use in all phases of sedation and general anaesthesia. It has several characteristics that make it superior to other commonly used anaesthetic agents in outpatient oral and maxillofacial surgery.4,7,8,9,10

The most significant advantages of propofol when used in outpatient surgical procedures include minimal side effects, controllable anaesthetic state, quick onset because of its rapid distribution, and rapid emergence from general anaesthesia as 
the blood concentration declines exponentially. The clearance of the drug is faster and the effective half-life is shorter (30 to 60 minutes). Hence, it has a rapid recovery of psychomotor and cognitive functions. $9,11,12,13,14,15,16,17$

Midazolam is another popular agent which is known to satisfy most of the requirements of dental practice. It is a wellestablished sedative agent for use in oral and maxillofacial surgery when used intravenously under local anaesthesia. ${ }^{18,19}$ It is commonly used in the emergency department to provide sedation prior to performing procedures such as wound debridement, laceration repair and reduction of dislocations. It is also known to be an effective drug in the treatment of generalised seizures, status epilepticus, and behavioural emergencies, particularly when intravenous access is not available. Midazolam can be used intravenously, intramuscularly, orally, nasally, and rectally. ${ }^{20}$

Its pharmacological actions are identical to those of other benzodiazepines which include sleep induction, sedation, anxiolysis and amnesia. Midazolam is different from other agents by virtue of its more rapid onset of clinical effects and shorter duration of action. ${ }^{20}$

The addition of midazolam to the propofol regimen decreases the propofol dose requirement while producing no additional consequences with respect to recovery characteristics, postoperative mood, incidence of postoperative dreams, and patient satisfaction. Immediate premedication with $2 \mathrm{mg}$ of IV midazolam before propofol infusion is known to produce increased sedation, amnesia, and anxiolysis. ${ }^{9,21,22,23}$

The present study was designed to assess the effects of low dose Midazolam and Propofol during third molar surgery under local anaesthesia to evaluate the level of sedation, haemodynamic changes, condition of the patient during surgery, patient satisfaction and opinion and post-operative amnesia.

\section{Objectives}

The present study was conducted to assess the effects of low dose Midazolam with Propofol during third molar surgery to evaluate-

1. Level of sedation.

2. Condition of the patient during surgery (Amnesia).

3. Patient satisfaction and opinion.

4. Post-operative amnesia.

5. Haemodynamic changes.

\section{MATERIALS AND METHODS}

This is a prospective study to determine efficacy of Midazolam with propofol for sedation in third molar surgery. Patients who reported to the Department of Dental and Maxillofacial surgery, KBN Teaching and General Hospital, who required third molar surgical removal, were approached to take part in the study.

\section{Inclusion Criteria}

- Patients who required third molar surgical removal.

- Patients who fulfil ASA (American Society of Anaesthesiologists) grade I and grade II.

- $\quad$ Patients aged more than 21 years of age.

\section{Exclusion Criteria}

- Patients who do not fulfil ASA grade I and grade II.
- Patients who are on any type of psychoactive medication, sedatives and hypnotics.

- Patients having positive history of any neuromuscular, musculoskeletal and cardiorespiratory disorders.

- $\quad$ Patients known to be allergic to used drugs.

Routine investigations were done. The study was approved by the local ethical committee. Informed consent was obtained from the patients before their inclusion in the study. A complete medical history was elicited from the patient during the first appointment and oral and radiographic examination was completed to confirm the need for the surgery.

\section{Procedure}

All patients were instructed to be nil per oral for 6 hours before the surgical appointment. Patients were explained that sedation was given to help them tolerate the surgery and reduce apprehension, and were instructed that during the surgery they would be asked to respond to the surgeon's commands, even though they will be sedated. They were asked to inform the surgeon if they felt pain during the procedure. ${ }^{9}$

Before sedation, all patients were asked to complete the ball bearing test to evaluate their psychomotor function. They were asked to carry beads with a tissue forceps from a cup containing 40 beads, to another cup within 40 seconds. The number of beads carried was recorded as the score. This test was repeated at $15^{\text {th }}, 30^{\text {th }}, 45^{\text {th }}$, and $60^{\text {th }}$ minute postoperatively.

Pre-operative baseline vital signs were monitored using a multi-parameter monitor.

Intravenous access was obtained using a 20-gauge intravenous cannula. Propofol was diluted to a concentration of $2 \mathrm{mg} / \mathrm{mL}$ by adding $200 \mathrm{mg}$ of Propofol to $80 \mathrm{~mL}$ Normal Saline (total $100 \mathrm{~mL}$ ). A volumetric infusion pump (Infusomat $P ® B$ Braun) was used for the continuous infusion of Propofol. The infusion rate was set after the specific dose was determined according to the body weight of the patient.

Patients were given $1 \mathrm{~mL}$ of $2 \%$ Xylocaine with Midazolam + Propofol, Midazolam $0.03 \mathrm{mg} / \mathrm{kg}$ as a bolus prior to the Propofol bolus dose of $0.7 \mathrm{mg} / \mathrm{kg}$ to reduce the pain of injection followed by a continuous infusion of $50 \mu \mathrm{g} / \mathrm{kg} / \mathrm{min}$. Propofol.

After $5^{\text {th }}$ minute of Propofol infusion, the local anaesthetic was injected at the surgical site. After onset of profuse local anaesthesia, the operation was started. Throughout the study, blood pressure, pulse rate, respiratory rate and peripheral oxygen saturation were monitored non-invasively every 5 minutes. 1,3

The level of sedation was recorded at the $5^{\text {th }}$ minute of sedation, the time of injection of local anaesthetic, during the operation and at the $5^{\text {th }}$ minute postoperatively, using a fivepoint scoring system. ${ }^{3}$

To evaluate the patient's opinion about sedation, a modified visual analogue scale (VAS) was used where 0 represents totally calm and relaxed, and 10 represents worst fear imaginable. ${ }^{3}$

The condition of the patient was evaluated by the surgeon during the injection of local anaesthetic and the operative procedure according to the following criteria. ${ }^{3}$ 
Amnesia was evaluated at $60^{\text {th }}$ minute and 1 week postoperatively by asking the patients whether they remember-

- Injection of local anaesthetic.

- The operation.

- The object that was shown at $20^{\text {th }}$ minute intraoperatively.

- $\quad$ Suturing.

- Journey to the inpatient clinic.

All side effects during sedation and post-operative period were recorded. One week after the operation, the patient was asked about the unexpected effects of this method as well as their opinion about it. All the data was collected on a proforma and tabulated. The results were subjected to relevant statistical analysis, and the conclusions drawn.

\section{RESULTS}

The patients were both male and female; and in the age group of 21 to 45 years. Patients were of ASA grade I and II physical status.

The sedation levels evaluated at different intervals of time are shown in Table 1 . Sedations levels at $5^{\text {th }}$ minute of infusion $3(12 \%)$ patients were in level 2, $11(44 \%)$ patients in level 3, $9(36 \%)$ patients in level 4 and $2(8 \%)$ patients were in level 5 of the sedation scale.

The distribution of sedation scale during injection of LA found to be $05(20 \%)$ patients were in level 2, 12 (48\%) patients in level 3 and 09 (36\%) patients in level 4 of the sedation scale. (Table 1)

The level of sedation during the operative procedure was found to be $03(12 \%)$ patients were in level 2, $18(72 \%)$ patients in level 3 and $4(16 \%)$ patients in level 4 of the sedation scale. (Table 1)

The level of sedation at $5^{\text {th }}$ min post operatively was found to be $11(44 \%)$ patients in Level 1 and $14(56 \%)$ patients in Level 2. (Table 1)

The patient condition and cooperation due to sedation was evaluated by the surgeon based on the state of the patient during the procedure. At the time of injection of LA, the patient condition and cooperation was rated excellent in 09 (36\%) patients, good in $14(56 \%)$ patients and poor in $02(08 \%)$ patients. (Table 2A). And during the operative procedure, patient condition and cooperation was rated excellent in 18 (72\%) patients, good in $06(24 \%)$ patients and poor in $1(04 \%)$ patient. (Table 2B).

The distribution of Amnesia at different time intervals is shown in (Table 3). Amnesia for the injection of local anaesthetic at one hour postoperatively was 56\% (14 patients). (Table 4A).

At first week of surgery $60 \%$ (15 patients) showed amnesia.

Amnesia for any uncomfortable situation during the procedure at one hour post-operatively was $72 \%$ (18 patients). At first week of surgery distribution of amnesia was 6\% (19 patients). (Table 4B).

Distribution of amnesia for object shown during the $20^{\text {th }}$ minute at one hour postoperatively $64 \%$ (16 patients). At first week of surgery $72 \%$ (18 patients) patients exhibited amnesia. (Table 4C).

Amnesia for suturing at one hour postoperatively was 56\% (14 patients). At first week of surgery $60 \%$ (15 patients) still had amnesia. (Table 4D).
Amnesia for shift to recovery room at one hour postoperatively showed $8 \%$ (2 patients) amnesia with $8 \%$ (2 patients) describing amnesia at the end of first week postoperatively. (Table 4E).

Patient's satisfaction towards the sedation technique was evaluated using a Modified visual analogue scale (VAS) where 0 represents totally calm and relaxed (highly satisfied), and 10 represents worst fear imaginable (unsatisfied). 20 (80\%) were well satisfied with the procedure (rated score 0 to 3 out of 0 $10)$. And 5 (20\%) patients were moderately satisfied with the procedure (rated score 4 to 6 out of $0-10$ ). (Table 5).

The haemodynamic parameters in were within the normal range and showed no major changes. (Table $6 \mathrm{~A}, \mathrm{~B}, \mathrm{C}, \mathrm{D}$ ).

\begin{tabular}{|c|c|c|c|c|c|}
\hline Time & Lev 1 & Lev 2 & Lev 3 & Lev 4 & Lev 5 \\
\hline $5^{\text {th }}$ min. of Infusion & 0 & 3 & 11 & 9 & 2 \\
\hline During LA & 0 & 5 & 12 & 8 & 0 \\
\hline During Procedure & 0 & 3 & 18 & 4 & 0 \\
\hline $5^{\text {th }}$ min. Post op & 11 & 14 & 0 & 0 & 0 \\
\hline \multicolumn{6}{|c|}{ Table 1. Distribution of Sedation } \\
Scale at Different time Intervals \\
\hline
\end{tabular}

\begin{tabular}{|c|c|c|}
\hline Patient's state & $\begin{array}{l}\text { Propofol + } \\
\text { Midazolam }\end{array}$ & $\%$ \\
\hline $\begin{array}{l}\text { Patient calm and cooperative. } \\
\text { (Excellent) }\end{array}$ & 9 & 36.0 \\
\hline $\begin{array}{l}\text { Patient a little nervous and a little } \\
\text { resistant to the procedure. (Good) }\end{array}$ & 14 & 56.0 \\
\hline $\begin{array}{l}\text { Patient is extremely nervous and very } \\
\text { resistant towards procedure. (Poor) }\end{array}$ & 2 & 8.0 \\
\hline Total & 25 & 100.0 \\
\hline \multicolumn{3}{|c|}{$\begin{array}{l}\text { Table 2A. Distribution of Patient's state during } \\
\text { Injection of Local Anaesthetic }\end{array}$} \\
\hline
\end{tabular}

\begin{tabular}{|c|c|c|}
\hline Patient's state & $\begin{array}{l}\text { Propofol + } \\
\text { Midazolam }\end{array}$ & $\%$ \\
\hline $\begin{array}{l}\text { Patient calm and cooperative. } \\
\text { (Excellent) }\end{array}$ & 18 & 72.0 \\
\hline $\begin{array}{l}\text { Patient a little nervous and a little } \\
\text { resistant to the procedure.(Good) }\end{array}$ & 6 & 24.0 \\
\hline $\begin{array}{l}\text { Patient is extremely nervous and very } \\
\text { resistant towards procedure. (Poor) }\end{array}$ & 1 & 4.0 \\
\hline Total & 25 & 100.0 \\
\hline \multicolumn{3}{|c|}{$\begin{array}{c}\text { Table 2B. Distribution of Patient's State } \\
\text { during the Operative Procedure }\end{array}$} \\
\hline
\end{tabular}

\begin{tabular}{|c|c|c|c|c|}
\hline Procedure & \multicolumn{2}{|c|}{$\mathbf{6 0}^{\text {th }}$ min } & \multicolumn{2}{c|}{ 1 week } \\
\hline Presence of Amnesia & No & Yes & No & Yes \\
\hline Injection of LA & 14 & 11 & 15 & 10 \\
\hline $\begin{array}{c}\text { Uncomfortable situation } \\
\text { during Procedure }\end{array}$ & 18 & 7 & 19 & 6 \\
\hline $\begin{array}{c}\text { Object shown } \\
\text { at 20 th minute }\end{array}$ & 16 & 9 & 18 & 7 \\
\hline \multicolumn{6}{|c|}{ Suturing } & 14 & 11 & 15 & 10 \\
\hline Shift to post op ward & 2 & 23 & 2 & 23 \\
\hline Table 3. Distribution of Amnesia at Different \\
Time Intervals during the Study \\
\hline
\end{tabular}




\begin{tabular}{|c|c|c|c|c|c|}
\hline \multirow{2}{*}{ Visit } & \multicolumn{3}{|c|}{ Injection of Local Anaesthetic } & \multirow{2}{*}{ Total } \\
\cline { 2 - 5 } & No & $\%$ & Yes & $\%$ & \\
\hline 60 Min. & 14 & 56.00 & 11 & 44.00 & 25 \\
\hline 1 Week & 15 & 60.00 & 10 & 40.00 & 25 \\
\hline \multicolumn{5}{|c|}{ Table 4A. Distribution of Amnesia } \\
for Injection of Local Anaesthetic \\
\hline
\end{tabular}

\begin{tabular}{|c|c|c|c|c|c|}
\hline \multirow{2}{*}{ Visit } & \multicolumn{4}{|c|}{ Shift to Recovery Room } & \multirow{2}{*}{ Total } \\
\cline { 2 - 5 } & No & $\%$ & Yes & \% & \\
\hline 60 Min. & 2 & 8.00 & 23 & 92.00 & 25 \\
\hline 1 Week & 2 & 8.00 & 23 & 92.00 & 25 \\
\hline \multicolumn{5}{|c|}{ Table 4E. Distribution of Amnesia } \\
for Shifting to Recovery Room \\
\hline
\end{tabular}

\begin{tabular}{|c|c|c|c|c|c|}
\hline \multirow{2}{*}{ Visit } & \multicolumn{4}{|c|}{$\begin{array}{c}\text { Uncomfortable Situation during the } \\
\text { operative procedure }\end{array}$} & \multirow{2}{*}{ Total } \\
\cline { 2 - 5 } & No & $\%$ & Yes & $\%$ & \\
\hline 60 Min. & 18 & 72.00 & 7 & 28.00 & 25 \\
\hline 1 Week & 19 & 76.00 & 6 & 24.00 & 25 \\
\hline Table 4B. Distribution of Amnesia for any Uncomfortable \\
Situation during the Operative Procedure \\
\hline
\end{tabular}

\begin{tabular}{|c|c|c|c|c|c|}
\hline \multirow{2}{*}{ Visit } & \multicolumn{4}{|c|}{ Object shown at $20^{\text {th }} \mathrm{min}$} & \multirow{2}{*}{ Total } \\
\hline & No & $\%$ & Yes & $\%$ & \\
\hline 60 Min. & 16 & 64.00 & 9 & 36.00 & 25 \\
\hline 1 Week & 16 & 64.00 & 9 & 36.00 & 25 \\
\hline \multicolumn{6}{|c|}{$\begin{array}{l}\text { Table 4C. Distribution of Amnesia for } \\
\text { Object shown at } 20^{\text {th }} \text { Minute }\end{array}$} \\
\hline
\end{tabular}

\begin{tabular}{|c|c|c|c|c|c|}
\hline \multirow{2}{*}{ Visit } & \multicolumn{4}{|c|}{ Suturing } & \multirow{2}{*}{ Total } \\
\cline { 2 - 5 } & No & $\mathbf{\%}$ & Yes & $\mathbf{\%}$ & \\
\hline 60 Min. & 14 & 76.00 & 11 & 24.00 & $\mathbf{2 5}$ \\
\hline 1 Week & 15 & 76.00 & 10 & 24.00 & $\mathbf{2 5}$ \\
\hline
\end{tabular}

\begin{tabular}{|c|c|c|}
\hline $\begin{array}{c}\text { Patient Satisfaction } \\
\text { (VAS 0-10) }\end{array}$ & \multicolumn{2}{|c|}{ Midazolam + Propofol } \\
\hline 0 & 0 & \\
\hline 1 & 2 & $\zeta$ \\
\hline 2 & 2 & \\
\hline 3 & \multicolumn{2}{|c|}{$16 \quad(80 \%)$} \\
\hline 4 & 5 & \\
\hline 5 & 0 & \\
\hline 6 & \multicolumn{2}{|c|}{$(20 \%)$} \\
\hline 7 & \multicolumn{2}{|c|}{$0)$} \\
\hline 8 & \multicolumn{2}{|l|}{0} \\
\hline 9 & \multicolumn{2}{|l|}{0} \\
\hline 10 & \multicolumn{2}{|l|}{0} \\
\hline $\begin{array}{c}\text { Table 5. Pat } \\
\text { Opinion }\end{array}$ & $\begin{array}{l}\text { Itisfaction a } \\
\text { e Sedation }\end{array}$ & \\
\hline
\end{tabular}

Table 4D. Distribution of Amnesia for Suturing

\begin{tabular}{|c|c|c|c|c|c|c|c|c|c|c|}
\hline \multicolumn{6}{|c|}{ Systolic Blood Pressure (SBP) } & \multicolumn{5}{|c|}{ Diastolic Blood Pressure } \\
\hline & $\mathbf{N}$ & Min & Max & Mean & SD & & $\mathbf{N}$ & Min & Max & Mean \\
\hline Pre Op & 25 & 108 & 138 & 122.4 & 7.2 & Pre Op & 25 & 64 & 92 & 80.48 \\
\hline LA & 25 & 102 & 136 & 121.3 & 7.6 & LA & 25 & 64 & 96 & 79.60 \\
\hline 10 min. & 25 & 106 & 138 & 120.6 & 7.6 & 10 min. & 25 & 64 & 96 & 79.36 \\
\hline 15 min. & 25 & 106 & 140 & 121.5 & 7.6 & 15 min. & 25 & 66 & 96 & 80.40 \\
\hline $20 \mathrm{~min}$. & 25 & 110 & 138 & 121.6 & 6.5 & $20 \mathrm{~min}$. & 25 & 66 & 90 & 79.60 \\
\hline $25 \mathrm{~min}$. & 25 & 108 & 138 & 121.8 & 7.3 & $25 \mathrm{~min}$. & 25 & 66 & 98 & 79.76 \\
\hline $30 \mathrm{~min}$. & 24 & 108 & 144 & 121.9 & 7.9 & 30 min. & 24 & 64 & 104 & 80.25 \\
\hline $35 \mathrm{~min}$. & 20 & 108 & 136 & 121.1 & 7.3 & 35 min. & 20 & 66 & 92 & 79.50 \\
\hline 40 min. & 17 & 114 & 132 & 121.4 & 5.5 & 40 min. & 17 & 74 & 86 & 80.35 \\
\hline $45 \mathrm{~min}$. & 12 & 112 & 134 & 121.3 & 5.5 & 45 min. & 11 & 76 & 90 & 80.55 \\
\hline 50 min. & 9 & 114 & 132 & 121.8 & 5.2 & 50 min. & 9 & 78 & 88 & 81.11 \\
\hline $55 \mathrm{~min}$. & 7 & 116 & 132 & 122.9 & 5.5 & 55 min. & 7 & 78 & 84 & 80.86 \\
\hline $60 \mathrm{~min}$. & 5 & 116 & 126 & 121.2 & 4.1 & 60 min. & 5 & 78 & 86 & 81.20 \\
\hline 65 min. & 5 & 118 & 126 & 121.6 & 3.3 & 65 min. & 5 & 78 & 92 & 82.40 \\
\hline 70 min. & 2 & 118 & 120 & 119.0 & 1.4 & 70 min. & 2 & 78 & 80 & 79.00 \\
\hline 75 min. & 0 & -- & -- & -- & -- & 75 min. & 0 & -- & -- & -- \\
\hline Post-op & 25 & 110 & 132 & 121.9 & 5.0 & Post OP & 25 & 68 & 86 & 80.64 \\
\hline
\end{tabular}

\begin{tabular}{|c|c|c|c|c|c|}
\hline & & Min & Max & Mean & SD \\
\hline Pre 0p & 25 & 96 & 99 & 97.36 & 0.95 \\
\hline LA & 25 & 94 & 99 & 96.36 & 1.35 \\
\hline 10 min. & 25 & 95 & 99 & 96.28 & 1.10 \\
\hline 15 min. & 25 & 94 & 99 & 96.28 & 1.21 \\
\hline 20 min. & 25 & 95 & 99 & 96.40 & 1.04 \\
\hline 25 min. & 25 & 95 & 99 & 96.44 & 1.00 \\
\hline 30 min. & 24 & 95 & 98 & 96.58 & 0.93 \\
\hline 35 min. & 20 & 96 & 99 & 97.00 & 0.86 \\
\hline 40 min. & 17 & 96 & 98 & 96.71 & 0.77 \\
\hline 45 min. & 12 & 95 & 98 & 96.33 & 0.89 \\
\hline 50 min. & 9 & 95 & 98 & 96.22 & 0.83 \\
\hline
\end{tabular}

\begin{tabular}{|l|c|c|c|c|c|}
\hline 55 min. & 7 & 95 & 98 & 96.43 & 0.98 \\
\hline 60 min. & 5 & 95 & 97 & 96.40 & 0.89 \\
\hline 65 min. & 5 & 96 & 98 & 96.80 & 0.84 \\
\hline 70 min. & 2 & 97 & 97 & 97.00 & 0.00 \\
\hline 75 min. & 0 & -- & -- & -- & -- \\
\hline Post-op & 25 & 96 & 99 & 97.60 & 0.71 \\
\hline \multicolumn{5}{|c|}{$\begin{array}{r}\text { Table 6B. Mean Oxygen Saturation } \\
\text { at Different Time Intervals }\end{array}$} \\
\hline
\end{tabular}




\begin{tabular}{|c|c|c|c|c|c|}
\hline & N & Min & Max & Mean & SD \\
\hline Pre-op & 25 & 15 & 21 & 17.84 & 1.43 \\
\hline LA & 25 & 14 & 16 & 14.84 & 0.75 \\
\hline 10 min. & 25 & 13 & 16 & 15.08 & 0.81 \\
\hline 15 min. & 25 & 13 & 17 & 15.48 & 1.05 \\
\hline 20 min. & 25 & 14 & 17 & 15.24 & 0.78 \\
\hline 25 min. & 25 & 14 & 18 & 15.52 & 0.96 \\
\hline 30 min. & 24 & 13 & 17 & 15.33 & 0.87 \\
\hline 35 min. & 20 & 13 & 17 & 15.45 & 1.19 \\
\hline 40 min. & 17 & 14 & 17 & 15.47 & 0.87 \\
\hline 45 min. & 12 & 14 & 17 & 15.17 & 0.83 \\
\hline 50 min. & 9 & 15 & 17 & 15.67 & 0.71 \\
\hline 55 min. & 7 & 15 & 16 & 15.29 & 0.49 \\
\hline 60 min. & 5 & 15 & 16 & 15.60 & 0.55 \\
\hline 65 min. & 5 & 15 & 16 & 15.40 & 0.55 \\
\hline 70 min. & 2 & 16 & 16 & 16.00 & 0.00 \\
\hline 75 min. & 0 & -- & -- & -- & -- \\
\hline Post-op & 25 & 15 & 19 & 15.88 & 0.93 \\
\hline \multicolumn{7}{|c|}{ Table 6C. Mean Respiratory Rate } \\
\hline
\end{tabular}

\begin{tabular}{|c|c|c|c|c|c|}
\hline & N & Min & Max & Mean & SD \\
\hline Pre-op & 25 & 65 & 112 & 80.08 & 11.03 \\
\hline LA & 25 & 64 & 112 & 77.64 & 10.96 \\
\hline 10 min. & 25 & 65 & 115 & 77.60 & 11.15 \\
\hline 15 min. & 25 & 61 & 108 & 79.72 & 11.43 \\
\hline 20 min. & 25 & 63 & 111 & 79.32 & 10.59 \\
\hline 25 min. & 25 & 62 & 109 & 80.68 & 11.07 \\
\hline 30 min. & 24 & 65 & 110 & 78.88 & 10.99 \\
\hline 35 min. & 21 & 63 & 108 & 77.67 & 10.27 \\
\hline 40 min. & 17 & 62 & 107 & 76.00 & 9.99 \\
\hline 45 min. & 12 & 65 & 103 & 77.25 & 9.90 \\
\hline 50 min. & 9 & 61 & 99 & 76.89 & 10.56 \\
\hline 55 min. & 7 & 66 & 98 & 74.86 & 11.16 \\
\hline 60 min. & 5 & 61 & 97 & 75.20 & 13.37 \\
\hline 65 min. & 5 & 62 & 99 & 76.20 & 13.95 \\
\hline 70 min. & 2 & 74 & 76 & 75.00 & 1.41 \\
\hline 75 min. & 0 & -- & -- & -- & -- \\
\hline Post-op & 25 & 66 & 88 & 75.96 & 5.37 \\
\hline \multicolumn{7}{|c|}{ Table 6D. Mean Pulse Rate between at } \\
\hline \multicolumn{7}{|c|}{ Different Time Intervals } \\
\hline
\end{tabular}

\section{DISCUSSION}

Surgery incites fear and apprehension among the patients. In oral and maxillofacial surgery, patients are generally more anxious and apprehensive and need some kind of sedation for better acceptability of the treatment.

A number of strategies are currently in use to reduce fear and anxiety in patients undergoing minor oral surgical procedures. These strategies include use of pharmacosedation, Iatrosedation and psychosedative techniques like Hypnosis.1,2.4 Pharmacosedation using intravenous technique gained popularity in the 1960 s. $^{1}$

Conscious sedation during intraoperative oral and maxillofacial surgery has been used to produce a clinical state of a relaxed, comfortable, co-operative, and cardiovascularly stable patient, who is able to maintain his own airway. ${ }^{1}$

Propofol and midazolam are the most often used intravenous anaesthetic agents in oral and maxillofacial surgery. Propofol has been preferred due to its short-acting

intravenous anaesthetic action with an excellent recovery profile. Various studies involving continuous propofol infusion have shown that it maintains oxygen level and haemodynamic stability by avoiding peaks and valleys of bolus administration. $1,2,3,4,5$

In the present study, Midazolam + Propofol was given, patients received a low dose Midazolam bolus of $0.03 \mathrm{mg} / \mathrm{kg}$ body weight followed by Propofol bolus of $0.7 \mathrm{mg} / \mathrm{kg}$ body weight IV, followed by Propofol continuous infusion of 50 microgram $/ \mathrm{kg}$ body weight $/ \mathrm{min}^{3}$

Patients were drowsy; eyes closed but arousable which provided an ideal condition for surgeon to perform surgery. The decrease in propofol dose requirement when it is used following the midazolam dose is reported in a study conducted by Cillo JE ${ }^{9}$ and others.

Midazolam is an effective anxiolytic and a good amnestic agent; this property has gained advantage so that it can be used along with propofol to produce synergistic action. The addition of low dose Midazolam prior to Propofol infusion has proven to reduce the dose of Propofol.3,9,10,15,20, 23

Pain along the vein on injection of propofol is common, and incidence of pain is seen among $33-50 \%$ of the patients who are given propofol bolus.11,24 In the present study, some patients had pain on administration at the injection site. Patients were given $1 \mathrm{~mL}$ of $2 \%$ xylocaine along with bolus dose of propofol to reduce the pain. Cillio J E reported that the amnestic effect is independent of the sedative effect. ${ }^{9}$

However, the doses of both the Propofol + Midazolam group used in the present study had least cardiovascular and respiratory effects and healthy patient cooperation leading to better operating conditions.

\section{CONCLUSION}

Based on the results of this study, the administration of low dose Midazolam prior to the infusion of Propofol improved the quality of sedation. The addition of Midazolam to Propofol provides a satisfactory level of sedation to both the patient and the surgeon. It produces good amnesia, which is advantageous in that the patient forgets unpleasant events. The recovery of psychomotor function was also found to be satisfactory

Hence, we conclude that the addition of low dose Midazolam to Propofol is a good and safe option for conscious sedation in minor third molar surgeries as it produces quality sedation without serious complications.

\section{REFERENCES}

[1] Malamed SF. Sedation: a guide to patient management. $4^{\text {th }}$ edn. Mosby, St. Louis 2003.

[2] Garip H, Gurkan Y, Toker K, et al. A comparison of midazolam and midazolam with remifentanil for patient-controlled sedation during operations on third molars. Br J Oral Maxillofac Surg 2007;45(3):212-6.

[3] Kucukyavuz Z, Cambazoglu M. Effects of low-dose midazolam with propofol in patient-controlled sedation (PCS) for apicectomy. Br J Oral Maxillofac Surg 2004;42(3):215-20.

[4] Moore PA, Finder RL, Jackson DL. Multidrug intravenous sedation: determinants of the sedative dose of midazolam. Oral Surg Oral Med Oral Pathol Oral Radiol Endod 1997;84(1):5-10. 
[5] Arya VS, Damle SG. Comparative evaluation of midazolam and propofol as intravenous sedative agents in the management of unto-operative children. J Indian Soc Pedo Prev Dent 2002;20(1):6-8.

[6] Berge TI. Nitrous oxide in dental surgery. Best Pract Res Clin Anaesthesiol 2001;15(3):477-89.

[7] Parworth LP, Frost DE, Zuniga JR et al. Propofol and Fentanyl compared with Midazolam and Fentanyl during third molar surgery. J Oral Maxillofac Surg 1998;56(4):447-53.

[8] Candelaria LM, Smith RK. Propofol infusion technique for outpatient general anesthesia. J Oral Maxillofac Surg 1995;53(2):124-8.

[9] Cillo JE. Propofol anesthesia for outpatient oral and maxillofacial surgery. Oral Surg Oral Med Oral Pathol Oral Radiol Endod 1999;87(5):530-8.

[10] Reinhart DJ, Grum DR, Berry J, et al. Outpatient anesthesia: a comparison of a combination of midazolam plus propofol and propofol alone. J Clin Anesth 1997;9(2):130-7.

[11] Rodrigo C, Irwin MG, Yan BSW, et al. Patient controlled sedation with propofol in minor oral surgery. J Oral Maxillofac Surg 2004;62(1):52-6.

[12] Cohen M, Eisig S, Kraut RA. Comparison of recovery of propofol and methohexital sedation using an infusion pump. Anesth Prog 1996;43(1):9-13.

[13] Zacny JP, Coalson DW, Young CJ, et al. Propofol at conscious sedation doses produces mild analgesia to cold pressor-induced pain in healthy volunteers. J Clinic Anesth 1996;8(6):469-74.

[14] Marinella MA. Propofol for sedation in the intensive care unit: essentials for the clinician. Respir Med 1997;91(9):505-10.
[15] Bennett J, Shafer DM, Efaw D, et al. Incremental bolus versus a continuous infusion of propofol for deep sedation/general anesthesia during dentoalveolar surgery. J Oral Maxllofac Surg 1998;56(9):1049-53.

[16] Steinbacher DM. Propofol: a sedative-hypnotic anesthetic agent for use in ambulatory procedures. Anesth Prog 2001;48(2):66-71.

[17] Vasileiou I, Xanthos T, Koudouna E, et al. Propofol: a review of its non-anaesthetic effects. Eur J Pharmacol 2009;605(1-3):1-8.

[18] Zacharias M, Bridgman J, Parkinson R. Two methods of administration of propofol for dental sedation. Br J Oral Maxillofac Surg 1998:36(1):19-23.

[19] Rodrigo C, Chow KC. A comparison of 1- and 3-minute lockout periods during patient-controlled sedation with midazolam. J Oral Maxillofac Surg 1995;53(4):406-10.

[20] Nordt SP, Clark RF. Midazolam: a review of therapeutic uses and toxicity. J Emerg Med 1997;15(3):357-65.

[21] Jerjes W, Jerjes WK, Swinson B, et al. Midazolam in the reduction of surgical stress: a randomized clinical trial. Oral Surg Oral Med Oral Pathol Oral Radiol Endod 2005;100(5):564-70.

[22] Bell GW, Kelly PJ. A study of anxiety and midazolaminduced amnesia in patients having lower third molar teeth extracted. $\mathrm{Br} \mathrm{J}$ Oral Maxillofac Surg 2000;38(6):596-602.

[23] Aitkenhead AR. Textbook of anesthesia. $5^{\text {th }}$ edn. Churchill Livingstone: Elsevier 2007.

[24] Pastuovic MN, Cohen ME, Burton RG. Propofol: an alternative general anesthetic for outpatient oral surgery. J Oral maxillofac Surg 1996;54(8):943-8. 